\section{A eficácia múltipla (ou a multiplicidade de um conceito antropológico)}

Fátima Tavares e Francesca Bassi (orgs.). Para além da eficácia simbólica: estudos em ritual, religião e saúde. Salvador, Edufba, 2013. 376 páginas.

\section{Gustavo Ruiz Chiesa}

Para além da eficácia simbólica é um livro múltiplo. Múltiplo não por contar com a colaboração de dezessete autores, nem por apresentar diferentes abordagens e percepções de um conceito já clássico na antropologia, mas porque apresenta a eficácia em sua multiplicidade (não unidade), "transformando-a", "deformando-a", "dobrando-a" de numerosas maneiras, sem cristalizá-la, sem tratá-la em um sentido único ou como algo externo, anterior e transcendente às práticas e relaçôes. O sentido da eficácia é estabelecido na relação, na prática, através dos múltiplos agenciamentos que mobiliza. Assim, a eficácia de uma experiência ritual, religiosa ou terapêutica não está fundamentada apenas em um conjunto de códigos, crenças e símbolos compartilhados em ações e contextos. Ao contrário, ou mais do que isso, o que torna um agenciamento eficaz não é o que ele representa, mas as transformaçôes e as afecções que ele provoca, os efeitos que produz, a adesão que implica; é, portanto, o que ele faz fazer. Tal proposição, sugerem alguns dos autores, nos permite repensar e problematizar uma série de totalidades ou dualismos como representação e ação, crenças e fatos, símbolos e práticas, indivíduo e contexto, natureza e cultura e, poderíamos acrescentar, teoria antropológica e prática etnográfica. São etnografias que produzem teorias e conceituações; são teorias baseadas em profundas experiências etnográficas. Em alguns capítulos - sobretudo na primeira parte do livro, "Revisitando conceitos" - essa problematização se manifesta de forma clara. Em outros em especial nas duas partes finais, "Ritual e transformação eficaz" e "Terapêuticas em contexto" - ela aparece de forma latente, menos explícita, mas não deixa de estar presente. De fato, esse questionamento, expresso de alguma maneira na própria epígrafe que cita Merleau-Ponty ("No homem tudo é natural e tudo é fabricado"), é certamente uma das principais contribuições da obra. Inspirados pelo próprio Merleau-Ponty, diríamos que a noção de eficácia, tal como pensada pelos autores (com destaque para o capítulo escrito pelas organizadoras), trata mais de uma "compreensão encorporada", de uma conjugação de afetos e pensamentos (p. 19), do que de um registro semântico, de um entendimento simbólico ou significativo de determinadas performances rituais, religiosas e terapêuticas.

Ao longo do livro, percorrendo os diferentes capítulos e autores, dois grandes "ancestrais" da antropologia são "invocados" à reflexão (ou melhor, à atuação). Tanto um quanto o outro, afirma Octavio Bonet em seu capítulo, se interessam por "fenômenos que se encontram na superfície de contato entre a dimensão simbólica e material do mundo" (p. 102). O primeiro, por motivos evidentes (expressos já no título do livro), é Claude Lévi-Strauss. O segundo, menos óbvio, mas não menos importante, é Marcel Mauss. Apesar de a noção de eficácia simbólica ter se popularizado sobretudo a partir dos dois ensaios de Lévi-Strauss sobre a cura xamânica entre os Cuna, no Panamá, no capítulo assinado por Sônia Weidner Maluf encontramos uma versão menos ortodoxa e enrijecida do conceito, apoiada justamente nas análises de Mauss e Hubert sobre a eficácia dos atos mágicos. Ideias como as de "experiência corporificada e afetiva", de "fusão entre causa e efeito", "entre símbolo e objeto", de "complementaridade entre ação mecânica e ação mágica", de "potencialidade ou força mágica" e de que os atos mágicos são "criadores e eficazes" produzindo "mudanças e transformaçôes" certamente se aproximam das recentes abordagens de autores como Jeanne Favret-Saada e Bruno Latour. Maluf reconhece que as ideias de experiência, agência e transformação também estiveram presentes na análise lévi-straussiana, mas não receberam a devida ênfase (sobrepostos que foram pela noção de "analogia", ideia-chave da análise estritamente estruturalista). Processos que envolvem eficácia religiosa, mágica e/ou terapêutica estão submersos em criatividade, imaginação e ação, aspectos essenciais de uma análise atenta à dimensão performática da cura e que, segundo a autora, também foram negligenciados ou pouco explorados por Lévi-Strauss. 
Em uma abordagem estruturalista, a eficácia simbólica (e a consequente cura) corresponderia à organização estrutural de eventos caóticos, ao ordenamento do mundo (desorganizado) dos afetos em um mundo mental, intelectual, organizado em um sistema simbólico. Nesse trabalho de reorganização, o xamã (bem como o psicanalista) fornece uma "língua" (mítica ou inconsciente, mas essencialmente afetiva, no sentido das afecções e experiências que provocam no doente), um conjunto de códigos e símbolos, que torna "pensável” uma situação dada inicialmente em termos afetivos e provoca o desbloqueio do processo fisiológico. Por sua vez, uma compreensão performática da eficácia simbólica afirmaria que determinada ação mágica ou ritual é eficaz não pelos seus aspectos lógicos ou semânticos, mas pela sua dimensão de "experiência corporificada”. Tal argumento tira o peso dado aos aspectos verbais e estruturais do ritual, apresentando-o como um "evento performático" responsável por produzir ou agenciar nos sujeitos uma experiência corporificada e afetiva - uma ideia que, de alguma maneira, não está ausente em Lévi-Strauss na medida em que a eficácia é, para ele, a produção de uma experiência específica. De todo modo, a ênfase nas analogias e metáforas, nas homologias e correspondências, nas regras e leis estruturais e em como fazem "sistemas" impede ou dificulta o nosso olhar sobre os agenciamentos e as práticas individuais ou coletivas. Como afirma Maluf (p. 52), "se para jogar, é preciso as regras, elas em si não são o jogo, o jogo de xadrez é o movimento das peças". Assim, ao apostar na dimensão pragmática, no "movimento das peças", na coreografia (e não na topografia, para utilizar a diferenciação sugerida por Laplantine), que a noção de eficácia nos oferece, podemos, em vez de acentuar um conjunto de regras e analogias estruturais, extrair da complexa ideia de eficácia simbólica contida em Lévi-Strauss "os aspectos em que questôes como ação e agenciamento, sujeito, invenção de si e do mundo, contexto e contingência emergem nas frestas de seu argumento" (p. 53). Como se tais aspectos estivessem de alguma maneira armazenados em uma das "dobras" que o conceito de eficácia simbólica em sua multiplicidade parece apresentar.

"Dobrando" um pouco mais e seguindo a leitura de Octavio Bonet sobre o conceito, esten- demos o entendimento da esfera simbólica, não mais atrelada (apenas) aos fenômenos sociais, mas completamente indissociável das dimensões psicológicas, fisiológicas e bioquímicas. Afinal, para Lévi-Strauss, as estruturas simbólicas são homólogas às estruturas corporais e cerebrais. Assim, bem ao gosto de Marcel Mauss, as fronteiras entre físico, psíquico e social se esvanecem, o simbólico deixa de ser definido em oposição a alguma outra coisa e passa a ser compreendido na conexão, na relação entre dimensões que, juntas, compõem uma "rede de significação". É nessa capacidade de estabelecer conexôes que residiria, segundo Bonet (p. 115), a eficácia dos símbolos. É "o poder das relaçôes”, "o poder do mundo interconectado", demostrando que "o mundo é uma rede".

Redes que, como mostra Francesca Bassi em seu capítulo sobre a eficácia das quizilas no candomblé nagô, são muitas vezes imprevisíveis, instáveis e variáveis porque fogem (criativamente) de qualquer sistema de classificação. Em relação às quizilas, a autora afirma que, mais do que representar ou simbolizar uma afiliação ao orixá, elas "fazem presente" o orixá por meio da eficácia de suas antipatias, suas sensações de repulsa, aversão e ojeriza a determinados elementos (alimentos, em sua maioria), provocando reações físicas no corpo do iniciado. "É a descoberta de uma alergia e de uma gastrite que comprova a efetividade das suas quizilas”, afirma Bassi (p. 213). Desse modo, o conhecimento sobre o seu orixá passa pelo corpo que experimenta, que é feito e afetado pela ação e presença de seu orixá. Trata-se de uma percepção somática do orixá, de um saber que pressupóe um sentir; um sentir (saber) que é individual porque leva em conta as idiossincrasias e sensibilidades de cada um. Esse saber sobre seu corpo, seu orixá e sua história se dá por meio de "indícios", "descobertas" e "acontecimentos" que provocam reaçōes, atualizam relações e produzem um determinado percurso biográfico. É nesse sentido (prático, vivido, criativo) que se constata a eficácia da quizila e não através de um conjunto de representações preexistentes, compartilhadas e transmitidas culturalmente. Do contrário, ou seja, ao reduzirmos fenômenos como esses - que incluem não só quizilas e orixás, mas também espíritos, fluidos, obsessões... - a aspectos 
puramente cognitivos e intelectivos, nós perderíamos "toda uma dimensão performática, imaginária e sensível” desses fenômenos, experiências e percepções nativas, de acordo com Marcelo Ayres Camurça (inspirado em Rita Segato) em seu capítulo sobre o espiritismo kardecista. Daí o empenho dos autores do livro em encontrar "categorias mais adequadas" (ou "revisitar" com novas abordagens antigos conceitos) para descrever experiências (religiosas e/ ou terapêuticas) que mobilizam, segundo Fátima Tavares (p. 262), “'agenciamentos eficazes', ou seja, que não envolvem representações sobre coisas, mas transformaçôes corporais importantes”. São eficazes justamente porque combinam pensamentos, afetos, imaginários, formas de organização social, rompendo, dessa forma, com qualquer possibilidade de dualismo conceitual do tipo "representação e prática", "razão e emoção", "mente e corpo", "indivíduo e sociedade" etc.

São categorias novas e "mais adequadas" como as de "agenciamento" (na qual as experiências religiosas/terapêuticas tornam-se múltiplas, flexíveis e moventes) e "acontecimento" (que reconhece modos ou processos de individuação não delimitáveis em entidades unívocas) - que implicam diferentes formas de pensar, perceber e se relacionar com o "nativo". Não se trata, nesse caso, de produzir um saber sobre algo ou alguém, ou mesmo de pensar e sentir como esse alguém, mas de um saber com alguém, apostando todas as fichas em seu caráter eminentemente relacional (e não essencialista).

Sob as limitações que o formato de uma resenha impõe, lamentavelmente não serei capaz de apresentar com profundidade todos os capítulos dessa extensa e já fundamental obra. Contudo, além dos autores mencionados, o livro também conta com as traduçôes de textos escritos por Michael Houseman (sobre práticas psicoterapêuticas e terapias sistêmicas), François Laplantine (com a proposta de um "modelo coreográfico" para os estudos antropológicos sobre o corpo), Arnaud Halloy (sobre a possessão no culto xangô de Recife, com ênfase à dimensão transformativa da incorporação) e Bertrand Hell (que, em diálogo com o texto de Halloy, propõe uma "antropologia da possessão" que dê conta do "sentido vivido" dessa experiência). Conta ainda com outros dois interessantes artigos de Carlos Caroso (a partir da etnografia escrita por Castaldi sobre três terapeutas religiosos na ilha de Itaparica) e de Xavier Vatin (que analisa as complexas relações entre música e possessão). Por fim, na terceira e última parte do livro, encontramos quatro capítulos atentos mais especificamente às práticas terapêuticas e às transformaçôes que elas exercem nos sujeitos que as vivenciam. De formas diferenciadas, a questão da adesão, do envolvimento, do cuidado e da confiança atravessa todas as práticas apresentadas nos excelentes textos de Claudia Barcellos Rezende (sobre os grupos de apoio às gestantes), Annette Leibing (que trata justamente das inúmeras problemáticas, descritas pelos enfermeiros, em torno da adesão dos idosos e doentes mentais ao tratamento médico), Rachel Aisengart Menezes (abordando o tema da "boa morte" e dos "cuidados paliativos") e Mónica Franch e Artur Perrusi (sobre o relacionamento entre casais sorodiscordantes). A resistência à normatividade médica, que não apenas controla e padroniza, mas também idealiza seus pacientes (atribuindo um "protagonismo" nem sempre desejado por eles), sejam gestantes, idosos, terminais ou soropositivos, é outro ponto em comum desses capítulos. Resistir significa reinterpretar, ressignificar e reexistir, criativamente, de outras maneiras, com outros agenciamentos. São práticas, permeadas por questôes morais, sociais, culturais, religiosas, fisiológicas, psicológicas, que, para além das representações e determinações médicas, de suas normas, de seus modelos de conduta e dos papeis sociais ("sugeridos pela coletividade") a serem cumpridos, implicam novos processos de subjetivação, de invenção de si, em diferentes e criativos modos de ser e estar no mundo.
GUSTAVO RUIZ CHIESA é doutorando em antropologia pela Universidade Federal do Rio de Janeiro. E-mail: gustavorchiesa@gmail.com. 